\title{
Scientists charged with choosing publication over public health
}

Dutch researchers are being accused of aggravating an outbreak of lymphogranuloma venereum, a re-emerging sexually transmitted disease (STD), by not alerting authorities. The scientists kept secret their knowledge of an early cluster of cases in order to publish their data in a ๖ research journal, according to a scathing report by the Dutch Health Care Inspectorate (IGZ) in The Hague.

Experts are investigating the infection's rise in Europe, the US and Canada. At least 357 cases of the disease, which is caused by Chlamydia trachomatis types 1,2 and 3, have been confirmed since 2002 in six European countries, with the sharpest increases in Paris and Amsterdam after the summer of 2003. Most of the cases are linked to men, many of them HIV-positive, who had unprotected anal sex with other men. Prior to that, only a handful of cases surfaced each year among female immigrants from African regions where the disease is endemic.

The Dutch report, based on accounts from unnamed workers at the clinic, charges that specialists at the STD clinic of the Erasmus Medical Center (EMC) in Rotterdam knew in July 2003 that 14 people had been infected by a patient known to have the disease, but kept it quiet. Authorities heard about the cases only after the researchers' first case report appeared in December (Sex. Transm. Infect. 79, 453-455; 2003). A subsequent national and European public health alert, issued in January 2004, uncovered an avalanche of additional cases, including 11 recently in the US.

IGZ officials say it is "very likely" that the lag in reporting exacerbated the outbreak. "We are convinced less people would have been infected without the delay, while others would have been treated sooner and been infectious more briefly," says Jan van Wijngaarden, IGZ's inspector for infectious diseases. "Precious time was lost during the early phase of the epidemic curve."

Doctors in the Netherlands are not automatically required to report cases of lymphogranuloma venereum, but the law instructs them to report 'unusual clusters' of any contagious disease.

The IGZ has said in a statement that it will lodge complaints with the Dutch medical disciplinary board against the head of the EMC's Department of Dermatology and Venereology, as well as the former and current heads of the department's STD clinic. Public documents show these positions are filled by Martino Neumann, Wim van der Meijden and Bing Thio, respectively. During hearings, Van Wijngaarden says, witnesses will testify that publication of a research paper was the motivation behind the reporting delay.
David Drexhage, a spokesman for the EMC and the accused researchers, says the IGZ report is "biased" and denies data were held back deliberately to safeguard a paper. "The researchers did not know the relevant section of the law or had not realized its scope," Drexhage says. "They think it is not yet scientifically proven and highly unlikely that the delay caused outbreaks elsewhere."

UK epidemiologist Kevin Fenton, a coordinator of the European network for surveillance of sexually transmitted diseases, says it is too early to tell whether the reporting delay aggravated the outbreak. "Even after the alert, many countries did not increase their surveillance," he says.

An international meeting on the outbreaks held on 15 April in Bilthoven, the Netherlands, showed that researchers are still in the dark about many key facts, including how many strains are spreading, where they came from and whether they represent the tip of an iceberg that has been submerged for years.

Still, events in Rotterdam have rattled the STD field, says Fenton. "Clearly it has focused us once again on the need to rightly balance our obligations as researchers as well as physicians."

Peter Vermij, Bilthoven

\section{Bugs gain vital ground in their battle against drugs}

A new antibiotic-resistant and virulent form of Staphylococcus aureus has surfaced in significant numbers in cities across the US. Researchers are concerned that this community-based strain might become resistant to stronger antibiotics, limiting options for treatment.

Driven by overzealous antibiotic use, bacteria often evolve resistance to antibiotics in hospitals. Drug-resistant Staphylococcus, in particular, has been a pernicious presence in hospitals for more than two decades.

More than $60 \%$ of Staphylococcus infections acquired in hospitals are from $S$. aureus resistant to methicillin and the class of first-line antibiotics called beta-lactams, which includes penicillin. But unlike most of these drug-resistant strains, up to $20 \%$ of resistant strains the researchers encountered in the new study sprang from outside hospital walls (N. Engl. J. Med. 352, 1436-1444; 2005).

"The molecular biology of these seems to have changed," says investigator Jeffery Hageman, an epidemiologist the US Centers for Disease Control and Prevention.

The new strain has a 'cassette' of genes that

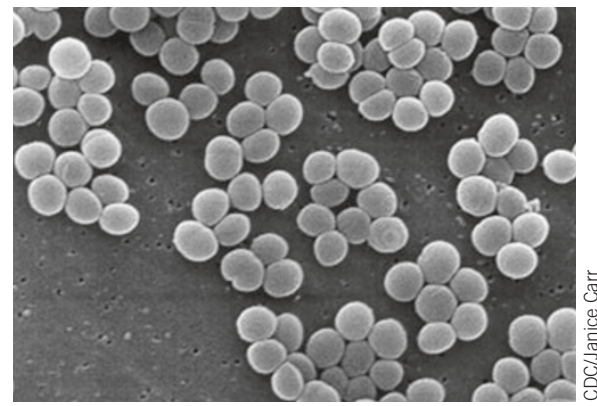

Rising Staph: Drug-resistant bacteria have emerged outside hospital walls in the US.

bestows resistance and which, at less than 24 kilobases, is more compact than those seen in resistant hospital strains. "What Staph has done is evolve a svelte, transmissible cassette," says Robert Daum, professor of microbiology at the University of Chicago.

The cassette may be small enough to hop to other kinds of Staphylococcus, perhaps carried by a phage that infects the bacteria, and confer antibiotic resistance to those strains. It may already be in up to ten clonal lines so far, says Henry Chambers, chief of infectious diseases at San Francisco General Hospital.

The new strain, universally described as "nasty," secretes more toxins and causes bigger lesions than some of its cousins. A second report says the strain caused "an alarming number" of cases of necrotizing fasciitis in a California hospital (N. Engl. J. Med. 352, 1445-1453; 2005). In that potentially fatal condition, the bacteria destroy the tissues underneath the skin at a rate of up to six inches an hour.

Clinicians may choose to treat patients infected with these strains with antibiotics such as vancomycin. But if that becomes standard practice, the bacteria might become resistant to these antibiotics as well, experts warn. Already a few scattered cases of vancomycin-resistant Staphylococcus infection have appeared in hospitals.

"Staph is an ancient pathogen," says Daum, who has evidence of yet another cassette of resistance genes - also small and promiscuous_-in Australia and Japan. "Whatever strategy we devise, it will come back with something. Viva la stalemate." Emma Marris, Washington DC 